بررسى إيدميولوزيك موارد مسموميت با گياهان و قارجها در بيماران بسترى بيمارستان لقمان حكيم تهران طى سالهاى بr -

سبيده ستارزاد فتحى '، حسين حسنيان مقدم؟، شاهين شادنياّ، نسيم زمانى ‘، ميترا رحيمى ه*

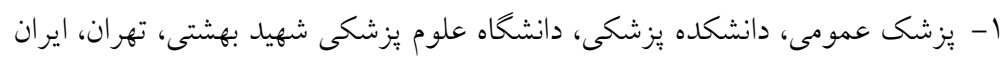

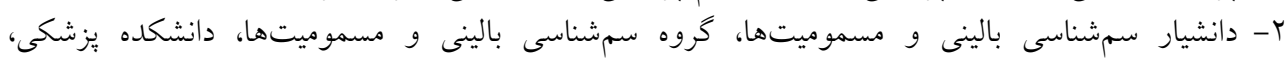

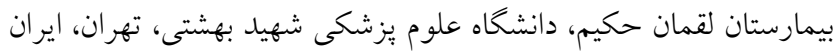

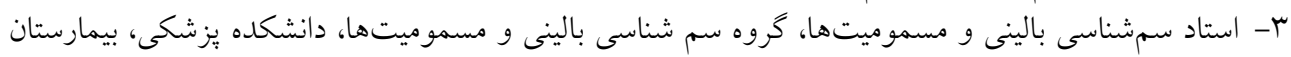

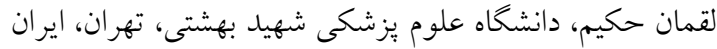

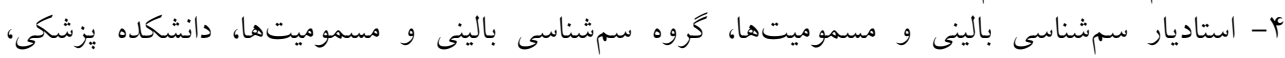

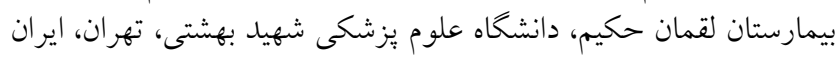

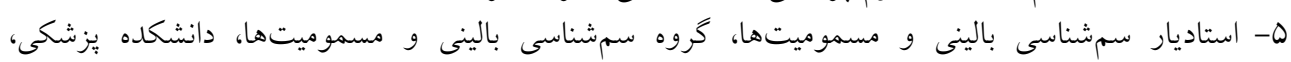

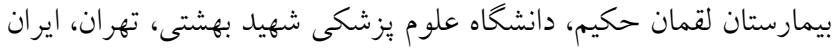

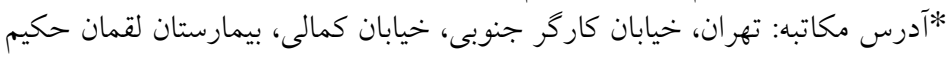

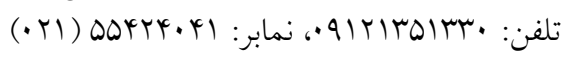
آدرس الكترونيك: mrahimi744@gmail.com

doi: $10.29252 / j m p .2 .70 .110$ 9V/T/N تاريخ تصويب

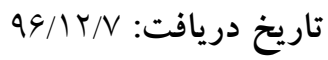

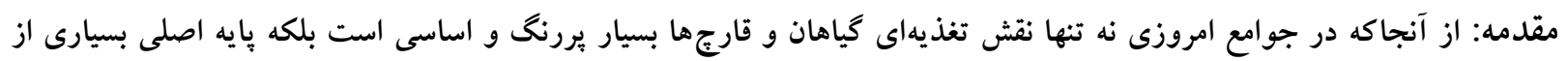

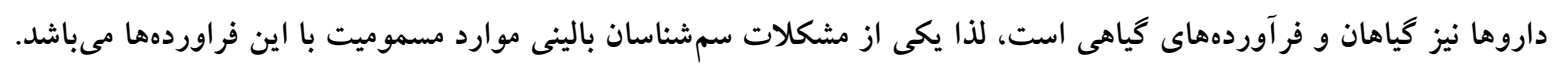

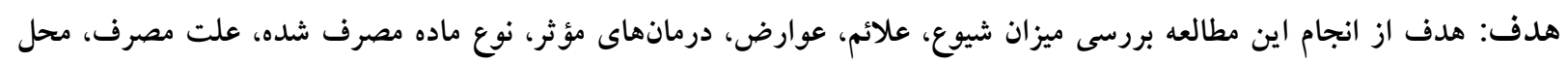

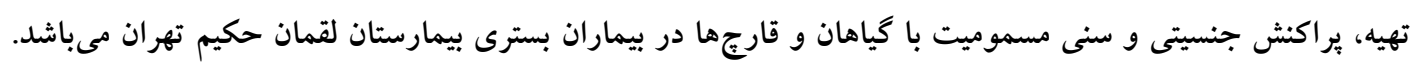

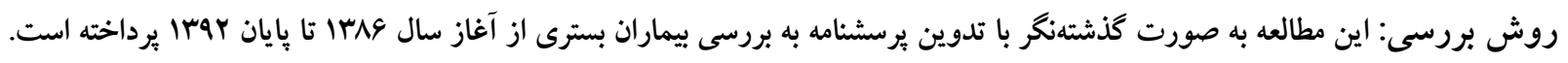

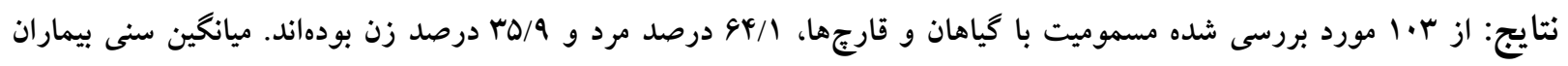

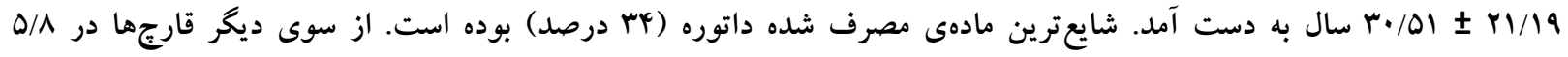

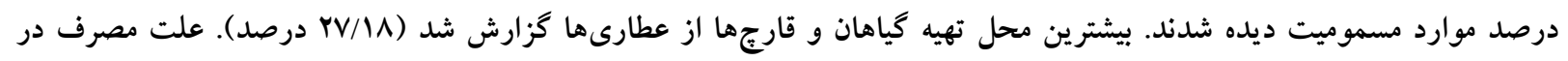

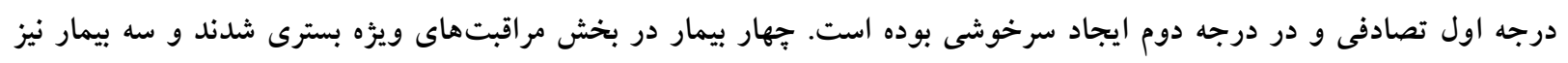

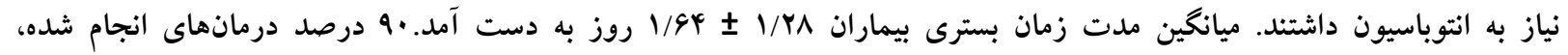

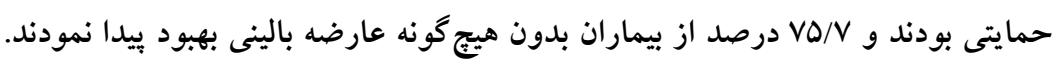

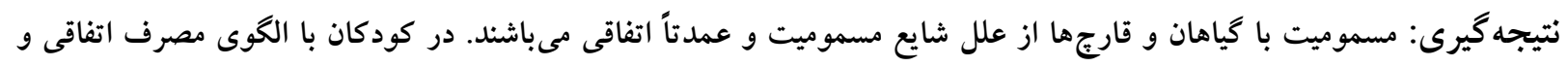

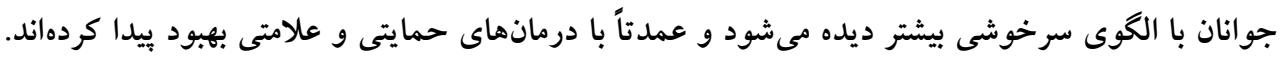

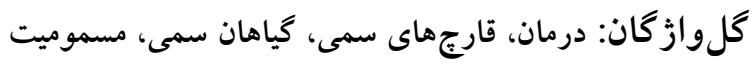


كياهان سمى حاوى تركيبات شيميايى متفاوتى شامل

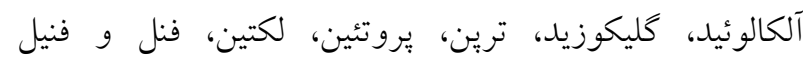

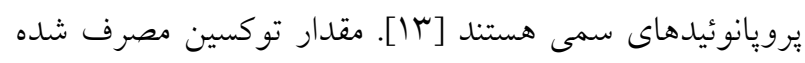

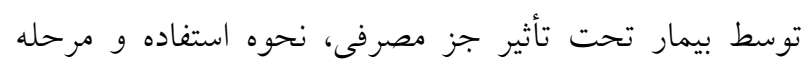

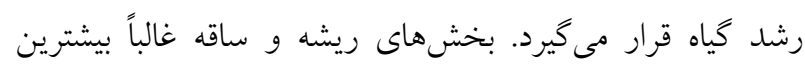

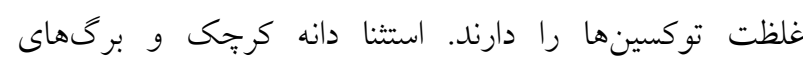
Rheum rhabarbarum جوشاندن برخى از كياهان همجيون Rhytolacca americana

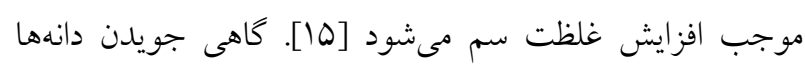

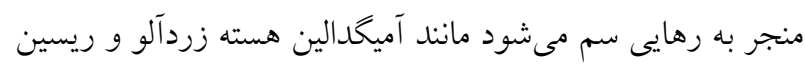

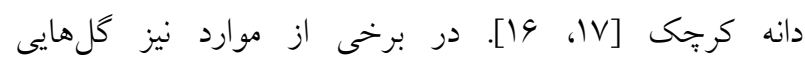

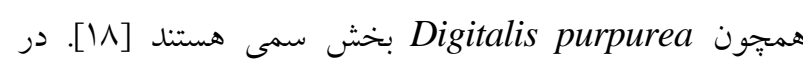
مورد كياهان ميوهدار مانند سيب آكى Blighia sapida ميوههاى نارس حاوى مقدار بيشترى از سم هستند [19].

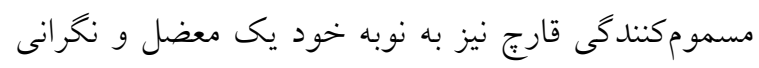

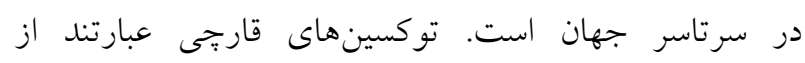
آماتوكسين (سيكلوييته)، ارلانوس (كونه هاى كورئ كورتيناريوس)،

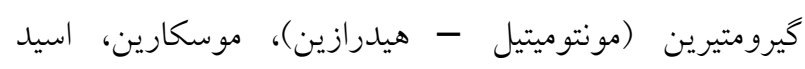

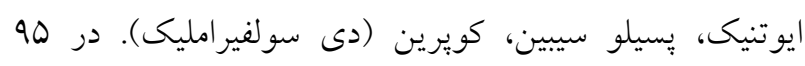

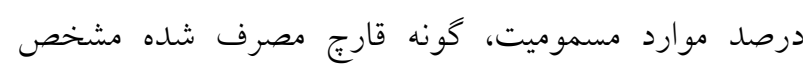

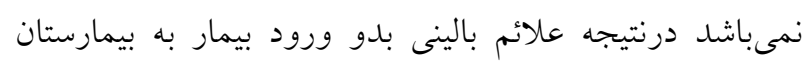

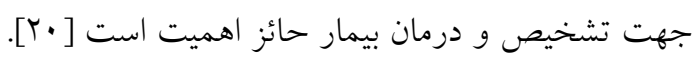

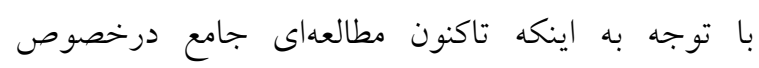

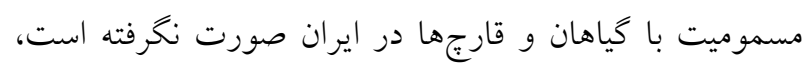
اين مطالعه با هدف بررسى اييدميولوزيك مسموميت با كياهان

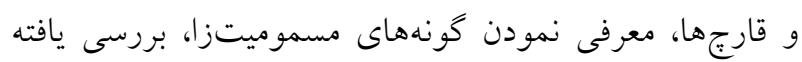

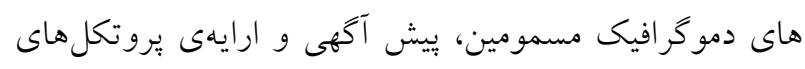
درمانى صورت كرفته است.
در جوامع امروزى مسموميتهاى ناشى از مصرف گياهان

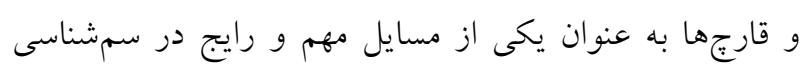
بالينى مطرح است. عدم وجود مطالعات دقيق، تجويز كياهان

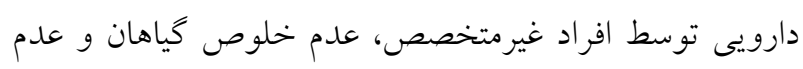

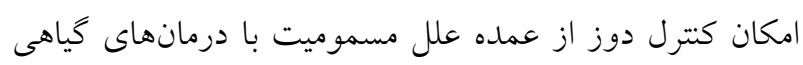

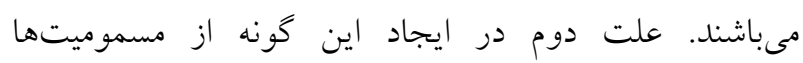

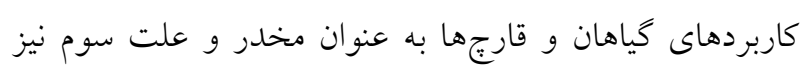

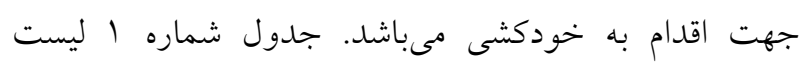

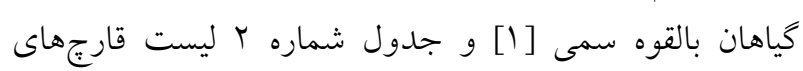

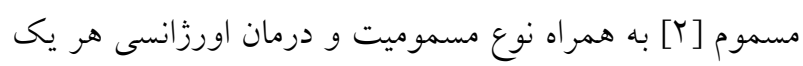
را نشان مىدهند. سابقهى مطالعهى شيوع مسموميت با كياهان و قارجها در در

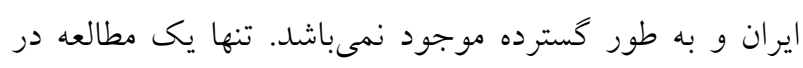

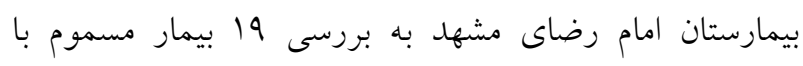

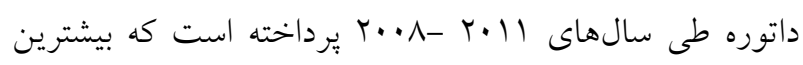

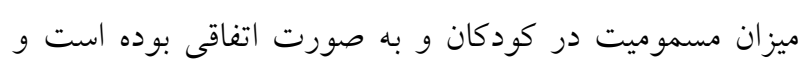
علائم عمدتاً بىقرارى و تاكى كاردى بوده است [َّ]. در آمريكا

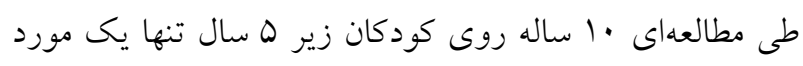

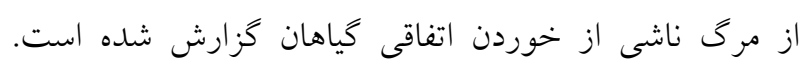

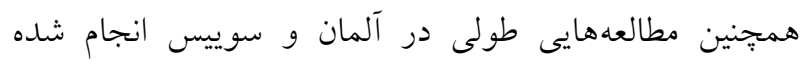

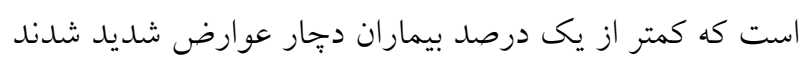

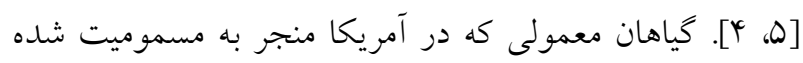

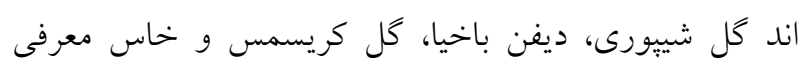

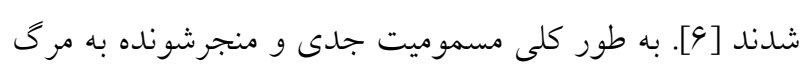

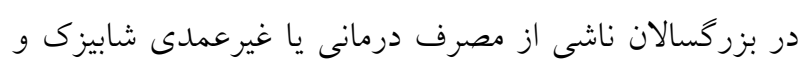

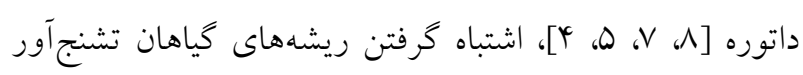

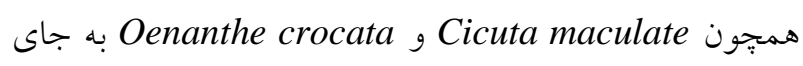

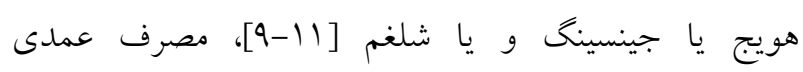
Thevetia peruviana 
جدول شماره 1- گياهان بالقوه سمى و اقدامات اورزانسى جهت درمان مسموميت ناشى از هر يك

\begin{tabular}{|c|c|c|c|}
\hline اقدام درمانى اقد إنسى & نوع مسموميت & بر اكنش جغر افيايى & نام متداول و علمى گياهان سمى \\
\hline- & كاستروآنتريت شديد، شوى هاييوولميك & سواحل درياى خزر & سرخاب كولى (Phytolacca americana) \\
\hline- & كَاستروآنتريت شديد، خونريزى از دستخاه & بخش هاى مركزى و & دانه كرجى (Ricinus communis) \\
\hline- & كأستروآنتريت شديد، خونريزى از دستخاه & - & جشم خر :جنكى (Abrus precatorius) \\
\hline- & هاستروآنتريت تأخيرى، از كار افتادگى ارگان & البرز، ت ت البران، خراسان & زعفران مرغزار (Colchicum autumnale) \\
\hline- & نكروز مخاط دستخاه گوارش، كما، يلى & & بهار سيب (Podophyllum peltatum) \\
\hline ديخو كسين & ضبرادى كاردى و تاكى كاردى، كاستروآنتريت، & كر ماحى شمالى مرتفع البرز & 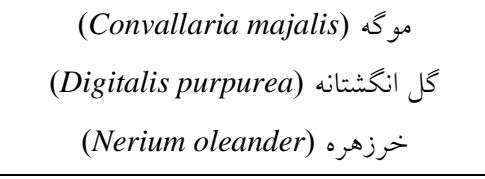 \\
\hline آترويين - إينفرين & 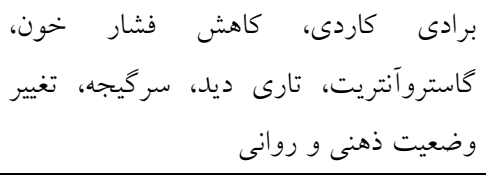 & 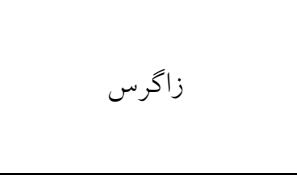 & 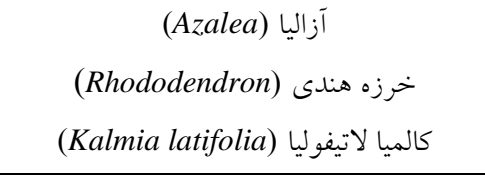 \\
\hline 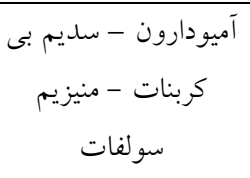 & 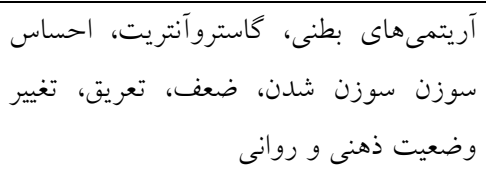 & - & تاججالملوى (Aconitum) \\
\hline آترويين - إينفرين & 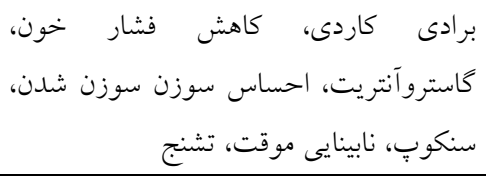 & - & وراتروم آلبوم (Veratrum album) \\
\hline آترويين - إينفرين - & 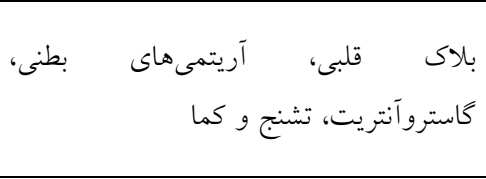 & جنغالهاى شمال كشور & سُخدار (Taxus baccata) \\
\hline آترويين & 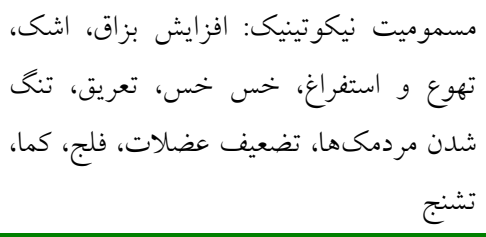 & تمام نواحى ايران & 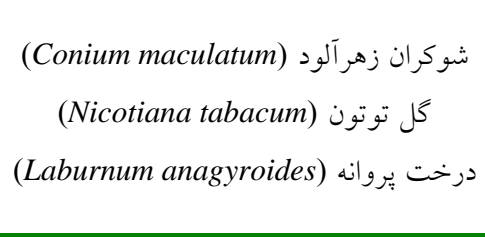 \\
\hline
\end{tabular}




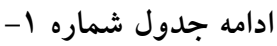

\begin{tabular}{|c|c|c|c|}
\hline اقدام درمانى اقدانى & نوع مسموميت & براكنش جغرافيايى & نام متداول و علمى گياهان سمى \\
\hline 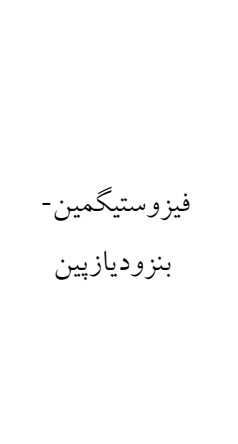 & 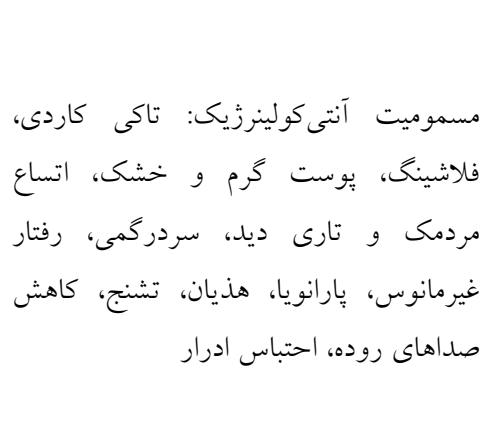 & 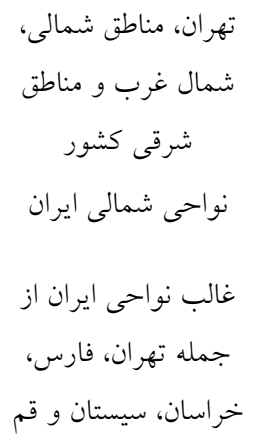 & 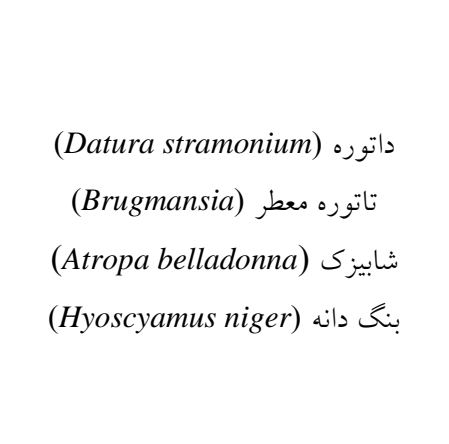 \\
\hline 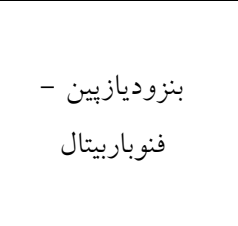 & 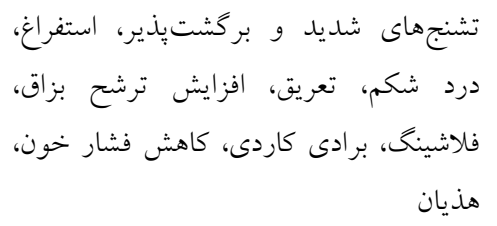 & - & آب شوكران آبى (Cicuta) \\
\hline بنزوديازيين & فلش بوهمات بصرى، استفراغ، تهوع، درد شكم، & - & رز جوبين هاو ايى (Argyreia nervosa) \\
\hline 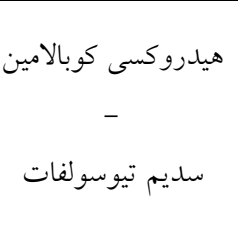 & 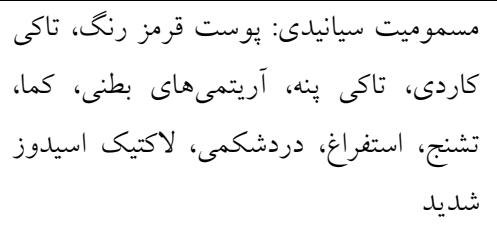 & - & يرونوس (Prunus) \\
\hline
\end{tabular}

جدول شماره Y - قارجهاى مسموم كننده به تفكيك نوع مسموميت و اقدام درمانى

\begin{tabular}{|c|c|c|}
\hline اقدام درمانى اورزانسى & نوع مسموميت & نام علمى قارج هاى مسموم \\
\hline جبران كمبود مايعات & كاستروآنتريت بدون از كار افتادگى كبد & $\begin{array}{c}\text { Chlorophyllum } \\
\text { molybdites } \\
\text { Clitocybe nebularis } \\
\text { Omphalates illudens }\end{array}$ \\
\hline بنزوديازيين & هالوسينوزنيك & $\begin{array}{c}\text { Psilocybe cubensis } \\
\text { P. mexicana } \\
\text { Conocybe cyanopus } \\
\text { Gymnopilus } \\
\text { aeruginosa } \\
\text { Panaeolousfoenisecil }\end{array}$ \\
\hline بنزوديازيين & 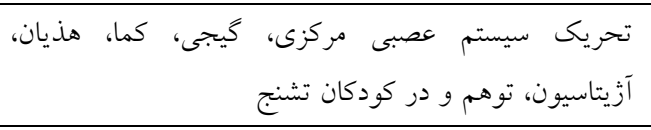 & $\begin{array}{c}\text { Amanita muscaria } \\
\text { A. pantherina } \\
\text { A. gemmata } \\
\end{array}$ \\
\hline جبران كمبود مايعات - كليكوييرولات - عالبوتامول - اييراتروييوم برومايد كولينرزيك - & 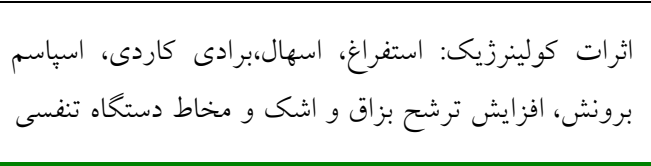 & $\begin{array}{l}\text { Clitocybe dealbata } \\
\text { C. illudens } \\
\text { Inocybe fastigiata } \\
\text { Boletus calopus }\end{array}$ \\
\hline
\end{tabular}




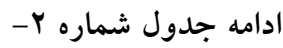

\begin{tabular}{|c|c|c|}
\hline 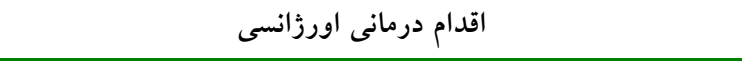 & نوع مسموميت & نام علمى قارج هاى مسموم \\
\hline 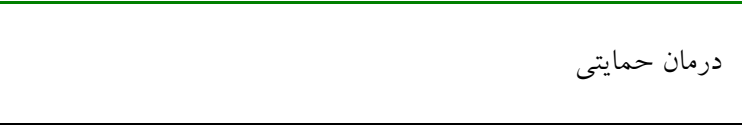 & 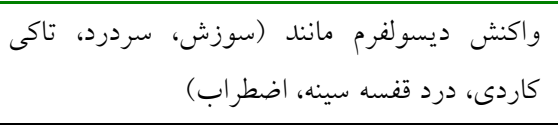 & $\begin{array}{c}\text { Coprinus } \\
\text { atramentarius } \\
\text { Clitocybe clavipes } \\
\end{array}$ \\
\hline 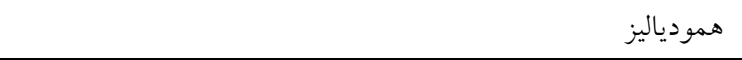 & كاستروآنتريت به همراه از كارافتادكى كليهها & Amanita smithiana \\
\hline 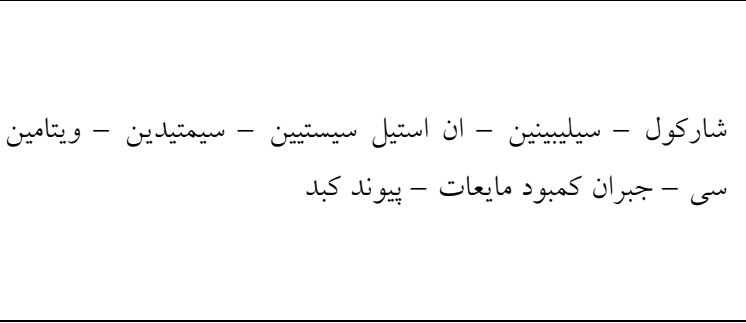 & مسموميت تأخيرى كبدى و كاستروآنتريت & $\begin{array}{c}\text { Amanita phalloides } \\
\text { A. virosa } \\
\text { A. verna } \\
\text { A. bisporigera } \\
\text { Galerina autumnalis } \\
\text { G. marginata } \\
\text { G. venenata } \\
\text { Lepiota helveola } \\
\end{array}$ \\
\hline بنزوديازيين - متيلن بلو - جبران كمبود مايعات & تشنج، كاستروآنتريت تأخيرى و مسموميت كبدى & $\begin{array}{c}\text { Gyromitra esculenta } \\
\text { G.infula } \\
\text { Sarcosphaera } \\
\text { coronaria } \\
\text { Cyathipodia } \\
\text { macropus } \\
\end{array}$ \\
\hline همودياليز - بيوند كليه & از كار افتادكى تأخيرى كليوى & $\begin{array}{c}\text { Cortinarius orellanus } \\
\text { C. speciosissinus } \\
\text { Mycena pura } \\
\text { Omphalatus orarius } \\
\end{array}$ \\
\hline جبران كمبود مايعات، اصلاح هايِر كالميا و همو دياليز & رابدوميليز تأخيرى & Tricholoma equestre \\
\hline درمان حمايتى كنترل كننده درد & و ورخدرد: درد بسيار شديد همراه با سوزش، اريتم & $\begin{array}{c}\text { Clitocybe } \\
\text { acromelalga }\end{array}$ \\
\hline درمان حمايتى & انسفالوياتى تأخيرى & Hapalopilus rustilans \\
\hline درمان حمايتى & كم خونى هموليتيك با واسطه سيستم ايمنى & Paxillus involutus \\
\hline آنتى هيستامين و كورتيكو استروييد & درماتيت Shiitake & Lentinula edodes \\
\hline كورتيكو استروييد، عوامل ضد قارج مانند آمفوتريسين بى & برونكوآلوئوليت آلرزيك & Lycoperdon species \\
\hline
\end{tabular}

جمع آورى شدهاند. همجِنين اصل رازدارى و حفظ حريم

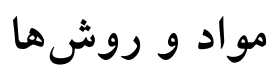
بيماران رعايت شده است.

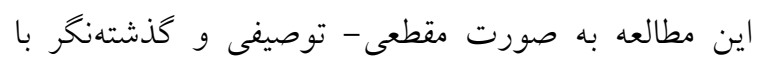
معيار ورود به مطالعه مسموميت با كياهان و قارجهائ بـاني

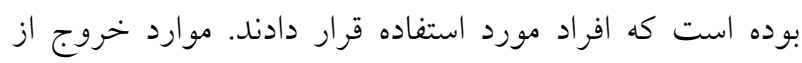

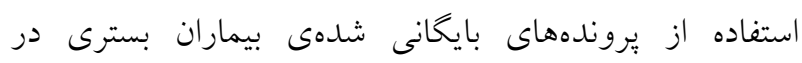

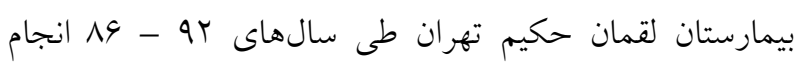
شده است. جامعلى هدف، بيماران بسترى شده به علت بهان مطالعه به ترتيب زير مىباشد: (1) هيدروكربنهاى كياهى كه

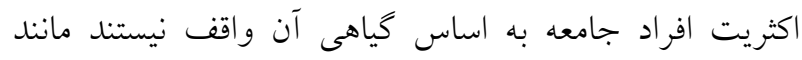

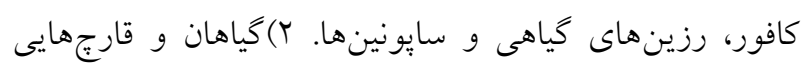

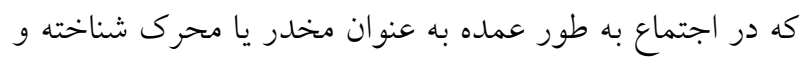

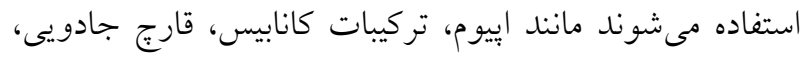

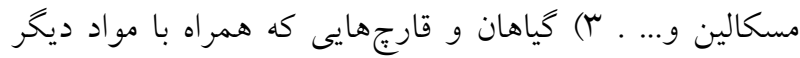

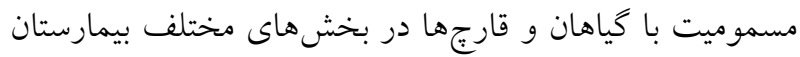
لقمان حكيم بودهاند. در اين مطالعه از يرسشنامه طراحى شده

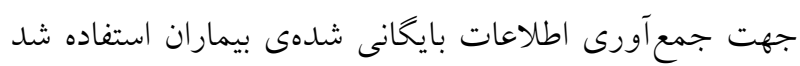

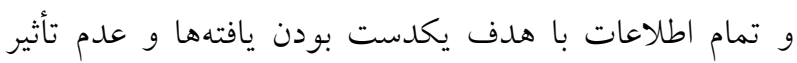

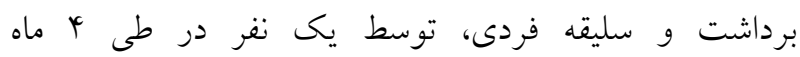


ميانگين مدت زمان ميان مصرف گياه و قارج توسط بيمار

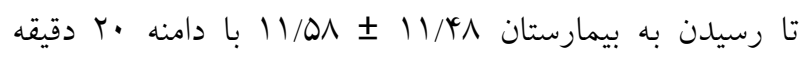

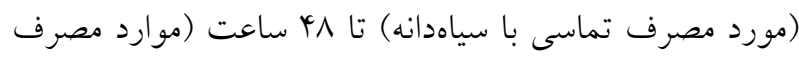

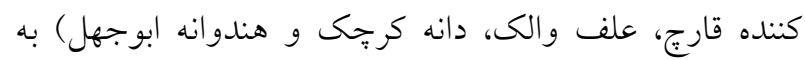

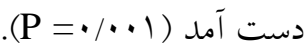

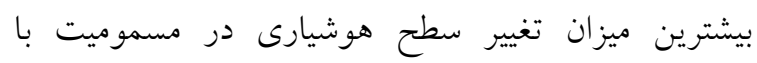

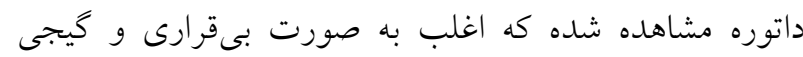

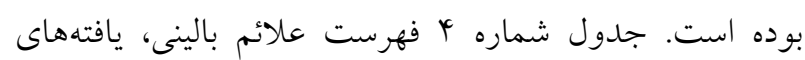

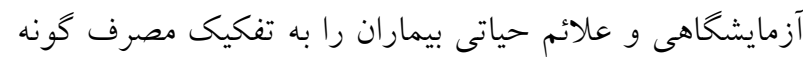
هاى گياهى و يا قارجى به تصوير كشيده است. جهار بيمار بيمار در بخش مراقبتهاى ويزه بسترى شدند (دو بيمار مصرف كننده

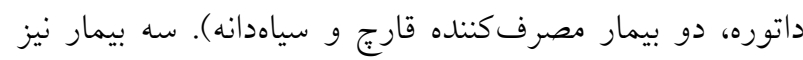

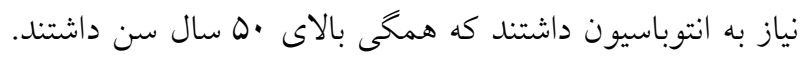

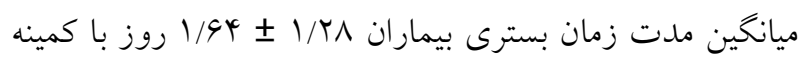

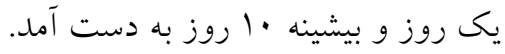
9 درصد درمانهاى انجام شده، حمايتى بودند و شامل

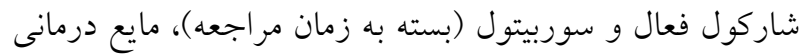
و ضدتهوع بودند. سٓ درصد بيماران بدو مراجعه تحت درمان

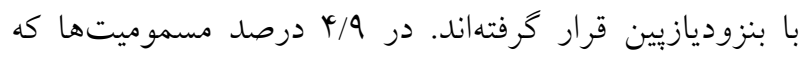

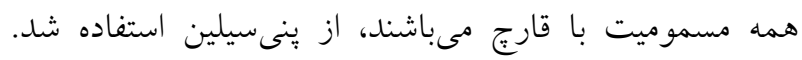

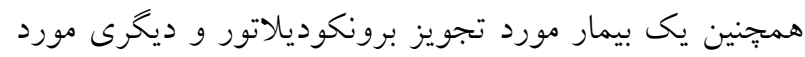
درمان با دگزامتازون به علت سوزش حلق و دهان قرار خرفتند. دو بيمار داراى سابقه بر فشارى خون بودند كه مورد درمان با بال

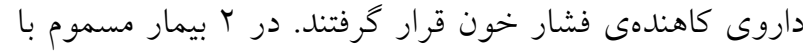

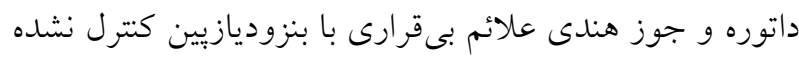

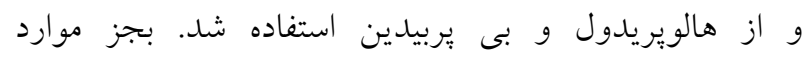

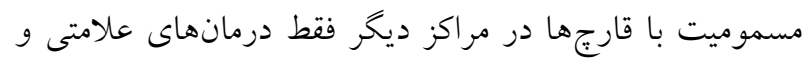

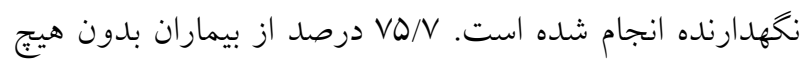

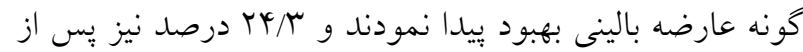
مرخص شدن نياز به follow up داشتند.
ماند قرصا، اسيدها و .. مصرف شدهاند. \&) داروهاى گياهى به علت احتمال عدم خلوص (V) المورد).

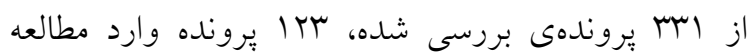

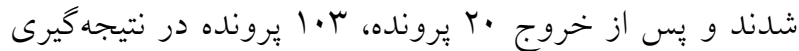

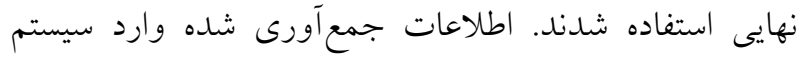

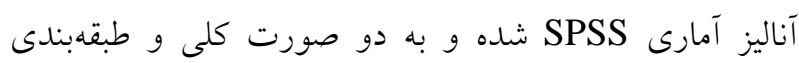

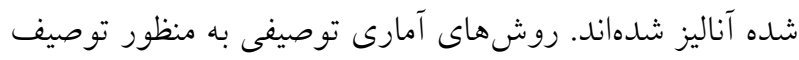

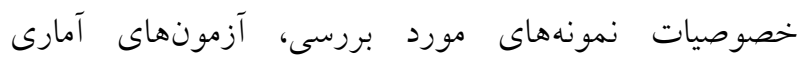

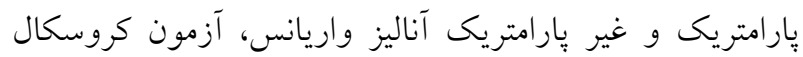

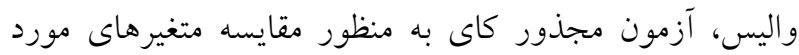
بررسى بين گروههاى مورد مطالعه انجام شدند.

\section{نتايج}

از ץ.1 مورد بررسى شده مسموميت با گياهان و قارجها،

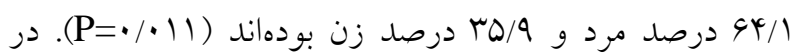
بررسى محل مسموميت D م درصد بيماران در تهران مسموم

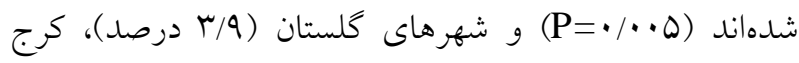
( T/Q درصد) و هشتخرد (r/9 درصد) به ترتيب بعد از تهران

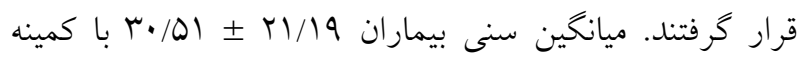

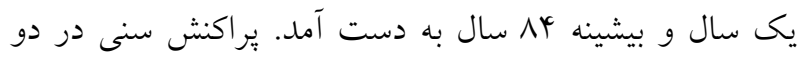

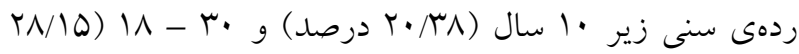

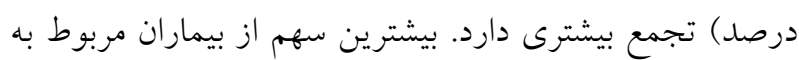
فصل زمستان بود (P= (P) (نمودار شماره ()).

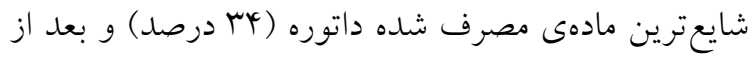

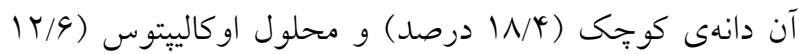

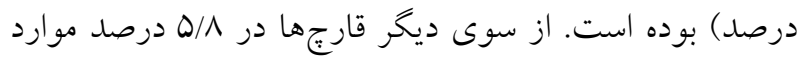
مسموميت ديده شدند. به جز يكى مورد مصرف تماسى بقديه

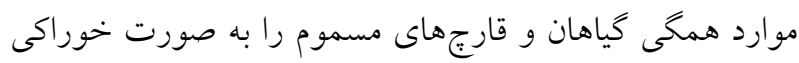

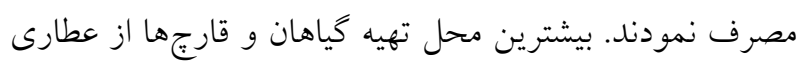
ها گزارش شد (NV/MN درصد). علت مصرف در درجه اول تصادفى و در درجه دوم ايجاد سرخوشى بوده است. قارجها

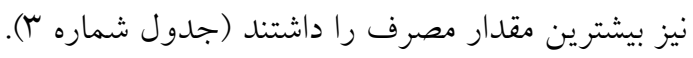




\section{الف:}

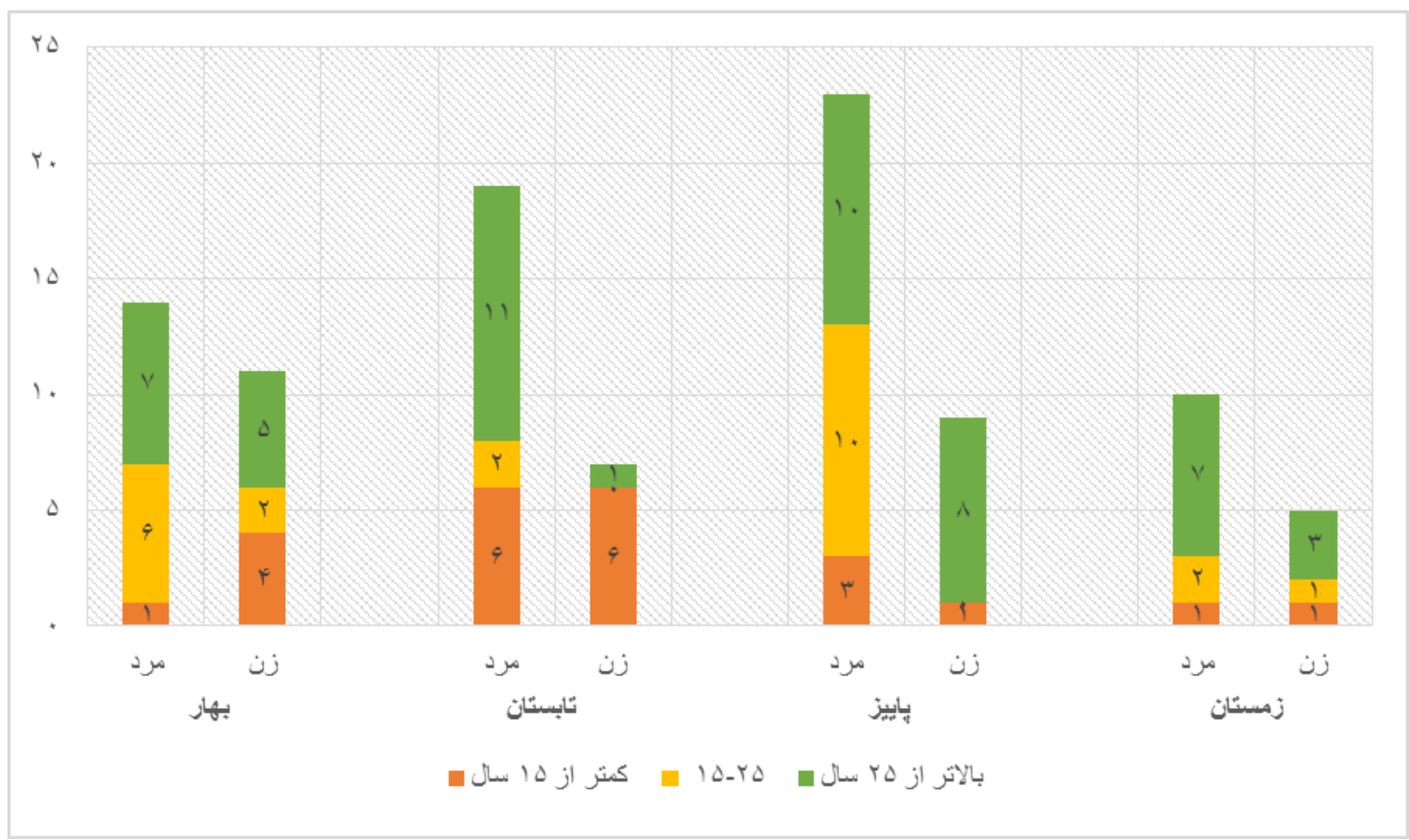

ب

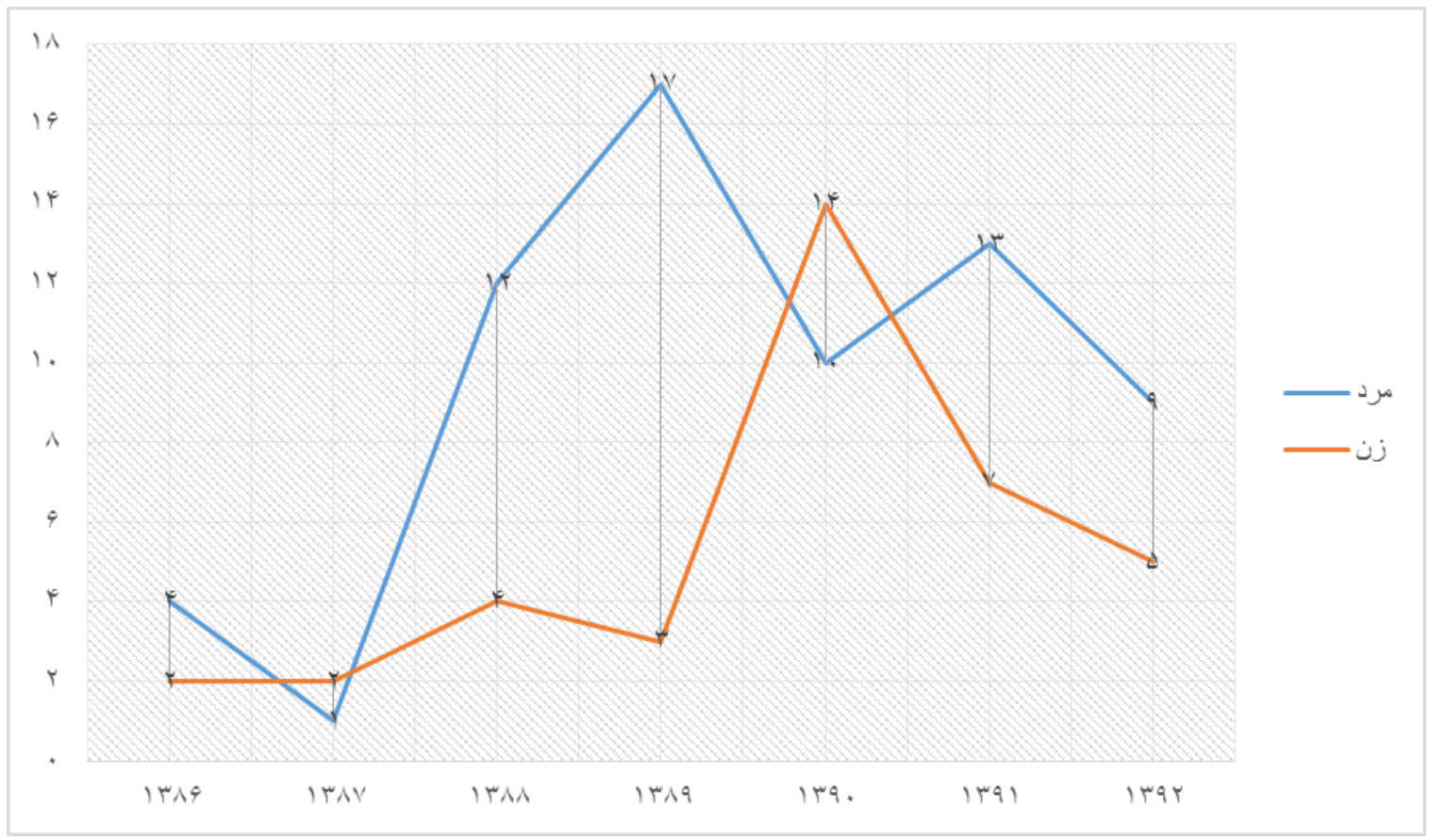

نمو دار شماره ا- بيماران وارد شده در اين مطالعه به تفكيك گروهاى سنى، جنس، فصل (الف) و سال مراجعه (ب) 
برسى إيدميولوزيكك موارد ...

جدول شماره r- فهر ست كياهان و قارجهاى سمى مصرف شده توسط بيماران اين مطالعه به تفكيك محل تهيه آنان و هدف از مصرف

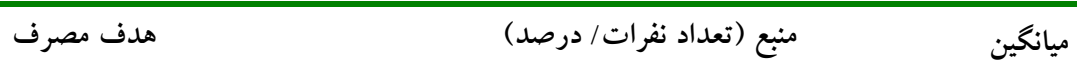

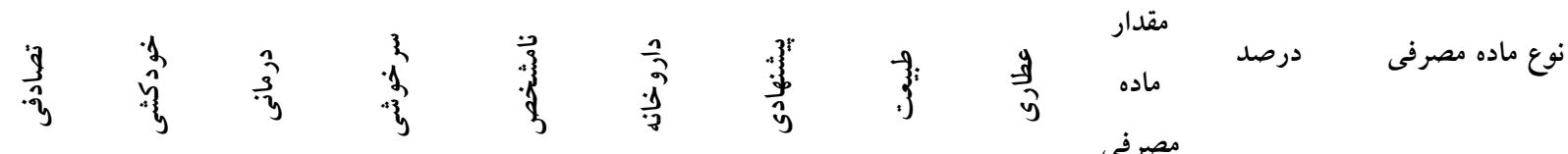

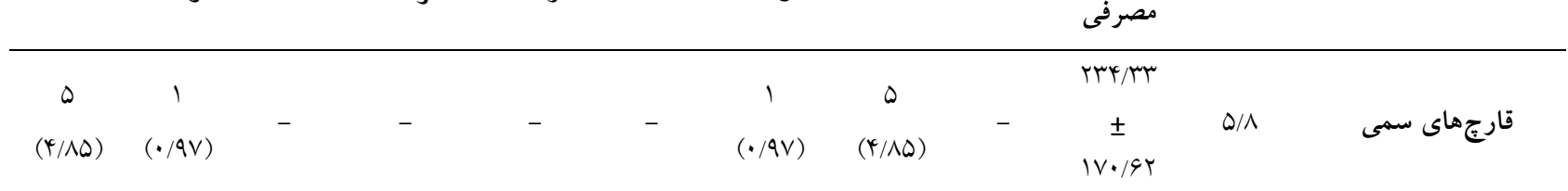

\begin{tabular}{|c|c|c|c|c|c|c|c|c|c|c|c|}
\hline $\begin{array}{c}\wedge \\
(V / V G)\end{array}$ & $\begin{array}{c}0 \\
(\Psi / \wedge \Delta)\end{array}$ & $\begin{array}{c}9 \\
(\Delta / \Lambda r)\end{array}$ & - & $\begin{array}{c}1 r \\
(11 / 90)\end{array}$ & - & $\begin{array}{c}r \\
(1 / 94)\end{array}$ & $\begin{array}{c}1 \\
(\cdot / 9 V)\end{array}$ & $\begin{array}{c}{ }^{\varphi} \\
(r / M \Lambda)\end{array}$ & $\begin{array}{c}9 / 09 \\
\pm \\
V / 19\end{array}$ & $11 / 4$ & دانه كرجָى \\
\hline $\begin{array}{c}1 \cdot \\
(9 / V \cdot)\end{array}$ & $\begin{array}{c}r \\
(r / 91)\end{array}$ & - & - & $\begin{array}{c}V \\
(9 / V q)\end{array}$ & $\begin{array}{c}9 \\
(Q / \Lambda Y)\end{array}$ & - & - & - & $\begin{array}{c}r V / \Lambda T^{4} \\
\pm \\
r Q / 4 .\end{array}$ & $1 Y / 9$ & اكاليتوس \\
\hline $\begin{array}{c}r \\
(r / 91)\end{array}$ & $\begin{array}{c}r \\
(r / 91)\end{array}$ & - & $\begin{array}{c}r q \\
(r N / \mid Q)\end{array}$ & $\begin{array}{c}0 \\
(\Psi / \wedge \Delta)\end{array}$ & - & $\begin{array}{c}10 \\
(14 / 09)\end{array}$ & $\begin{array}{c}0 \\
(\Psi / \wedge \Delta)\end{array}$ & $\begin{array}{c}1 \cdot \\
(9 / v \cdot)\end{array}$ & - & My & داتوره \\
\hline - & - & $\begin{array}{c}r \\
(1 / 9 r)\end{array}$ & - & - & - & - & - & $\begin{array}{c}r \\
(1 / 9 r)\end{array}$ & - & $1 / 9$ & هندوانه ابوجهل \\
\hline $\begin{array}{c}0 \\
(\Psi / \wedge \Delta)\end{array}$ & - & - & - & - & - & - & $\begin{array}{c}\Delta \\
(\Psi / \wedge \Delta)\end{array}$ & - & - & $r / q$ & كل ابريشم \\
\hline $\begin{array}{c}4 \\
(\Delta / \Lambda T)\end{array}$ & - & - & - & - & - & - & $\begin{array}{c}9 \\
(\Delta / \Lambda Y)\end{array}$ & - & - & $\Delta / \Lambda$ & اقاقيا \\
\hline $\begin{array}{c}r \\
(r / 91)\end{array}$ & - & - & - & - & - & - & $\begin{array}{c}r \\
(r / 91)\end{array}$ & - & - & $r / 9$ & علف والك \\
\hline - & - & $\begin{array}{c}1 \\
(\cdot / 9 V)\end{array}$ & - & - & - & - & - & $\begin{array}{c}1 \\
(\cdot / 9 V)\end{array}$ & - & 1 & برى سنا \\
\hline- & - & $\begin{array}{c}r \\
(1 / 9 r)\end{array}$ & - & - & - & - & - & $\begin{array}{c}r \\
(1 / 9 Y)\end{array}$ & - & $1 / 9$ & سياهدانه \\
\hline - & - & $\begin{array}{c}1 \\
(\cdot / 9 \mathrm{~V})\end{array}$ & - & - & - & - & - & $\begin{array}{c}1 \\
(\cdot / 9 V)\end{array}$ & - & 1 & جوز هندى \\
\hline $\begin{array}{c}r \\
(1 / 94)\end{array}$ & - & - & - & - & - & - & $\begin{array}{c}r \\
(1 / 9 r)\end{array}$ & - & - & $1 / 9$ & ميوه وحشى \\
\hline- & - & $\begin{array}{c}\wedge \\
(V N G)\end{array}$ & - & - & - & - & - & $\begin{array}{c}\wedge \\
(\mathrm{V} / \mathrm{V})\end{array}$ & - & $\mathrm{V} / \mathrm{A}$ & جاى گياهى \\
\hline \multicolumn{4}{|c|}{.000} & & & .000 & & & \multicolumn{2}{|c|}{.006} & P-value \\
\hline
\end{tabular}


جدول شماره ץ- فهرست علايم بالينى، علايم حياتى و يافته هاى آزمايشكاهى بيماران وارد شده در اين مطالعه

\begin{tabular}{|c|c|c|c|}
\hline P-value & قارجهاى سمى & كَاهان سمى & يافته ها (ميانگين / درصد) \\
\hline$\cdot / \cdot \operatorname{tr}$ & & $(9 / V q) \vee$ & تنخى نفس \\
\hline$\cdot / \cdots$ & & $(K Y / V I) Y^{4}$ & تهو \\
\hline$\cdot / \cdots$ & & $(\mid Y / G Y) \mid r$ & اسهال \\
\hline$\cdot / \cdots$ & $(1 / 9 Y) r$ & $(11 / 90) \mid r$ & درد شكم \\
\hline \multirow[t]{2}{*}{$\cdot \cdots$} & & 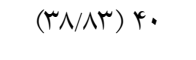 & استفراغ \\
\hline & & $(1 / 9 Y) r$ & 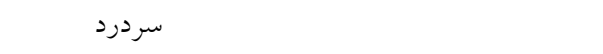 \\
\hline \multirow[t]{3}{*}{$\cdot / \cdot r$} & $(\cdot / 9 V) 1$ & $(1 \% / 09) \mid 4$ & سريجه \\
\hline & $\left.(1 / 9)^{r}\right) r$ & $(V / V \varphi) \wedge$ & ضعف \\
\hline & $(r / 91) r$ & $(9 / v \cdot)) \cdot$ & علايم بالينى \\
\hline \multirow[t]{4}{*}{$\cdot \cdots$} & & $(Y G / T I) Y V$ & توهم \\
\hline & & $(r / 91) r$ & 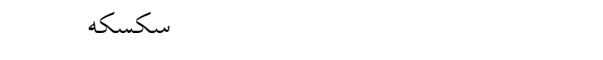 \\
\hline & & $(\Gamma / \Lambda \Lambda){ }^{+}$ & سوزش حلق \\
\hline & & $(\Delta / \Lambda T) \&$ & قرمزى جشم \\
\hline \multirow[t]{2}{*}{$\cdot / \cdot 1 r$} & & $(1 / 94) r$ & ت تشنج \\
\hline & & $(r / 91) r$ & آتاكسى \\
\hline$\cdot \cdots$ & & $(Y Y / T V) T Q$ & آزيتاسيون \\
\hline$\cdot / \cdots$ & & $(T Q / Y Y) Y G$ & كشادى مردمكى \\
\hline$\cdot / \cdots$ & & $\left(\mu^{\prime} / \wedge 9\right) \mu_{\Lambda}$ & كاهش سطح هوشيارى \\
\hline$\cdot / \cdot r$ & $\Lambda 1 / 99 \pm \Delta / r V$ & $94 / 11 \pm 19 / 11$ & ضربان قلب \\
\hline \multirow{10}{*}{$\cdot / \cdot r t$} & & $(9 / V 9) \vee$ & تعداد تنفس غير طبيعى \\
\hline & 111/rTITr/l9 & $11 \% / 10 \pm T r / 19$ & فشار خون سيستوليك \\
\hline & $G K / \mu T \pm T V / r Q$ & $V Y / G T \pm 1 Y / I V$ & فشار خون دياستولى \\
\hline & & $(19 / 41) Y$. & شمارش كامل خون \\
\hline & $\left.(1 / 9)^{r}\right) r$ & $(Y V / \backslash \Lambda) Y \Lambda$ & نيتروزن اوره خون \\
\hline & $(\cdot / 9 V) 1$ & $\left(\Lambda / V{ }^{\mu}\right) q$ & كراتينين \\
\hline & & $(1 / 9 r) r$ & علايم آزمايشگاهى غير طبيعى آسيارتات ترنس آميناز \\
\hline & & $(\cdot / 9 V) 1$ & آلانين ترنس آميناز \\
\hline & $(\cdot / 9 V) 1$ & $(\psi / \wedge Q) \Delta$ & آلكالن فسفاتاز \\
\hline & & $(1 \cdot / 9 \mathrm{~V}) 11$ & كازهاى خون \\
\hline
\end{tabular}

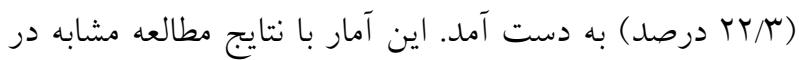

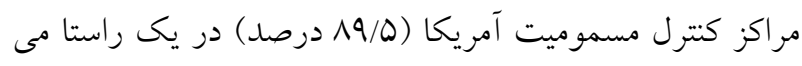

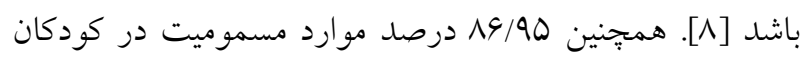

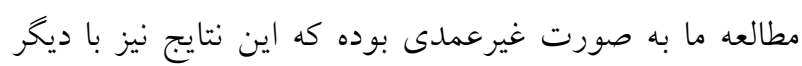

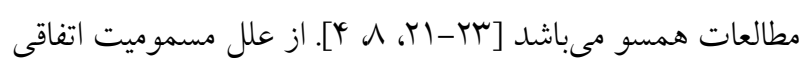

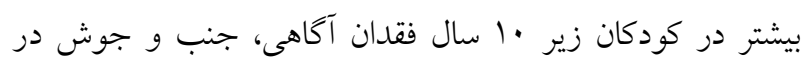
كودكان نويا، ناتوانى در تشخيص درست از اشتباه، عدم تمايز غذان إنا

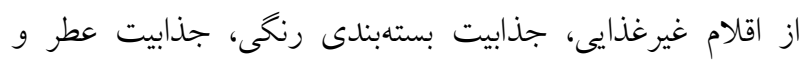

مسموميت با كياهان و قارجها از علل شايع مسموميت و

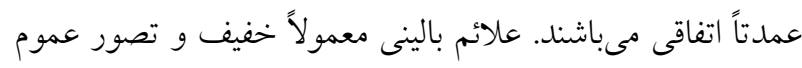

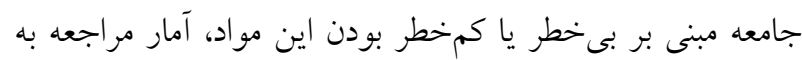

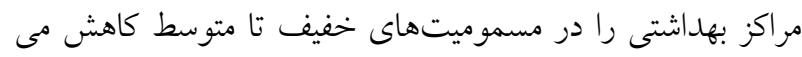
دهد. اين بيماران در تمام گروههاى سنى ديلده مى دشوند.

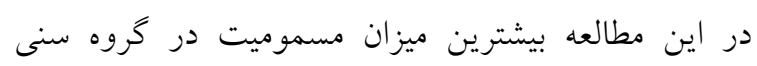

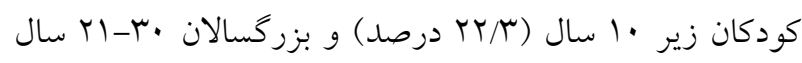


بيمارستان مراجعه نمى كنند. موارد شديدتر كه نياز به بسترى

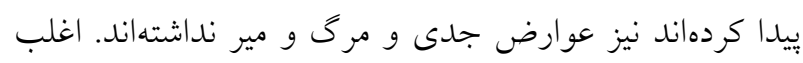

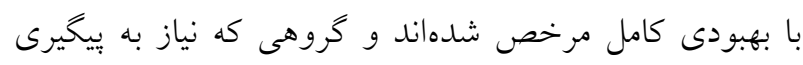

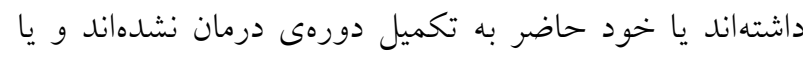

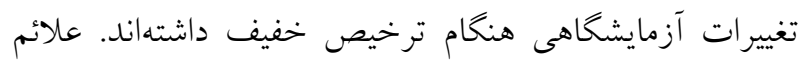

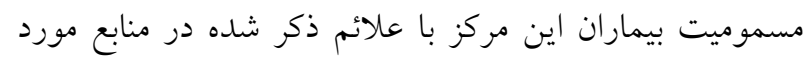

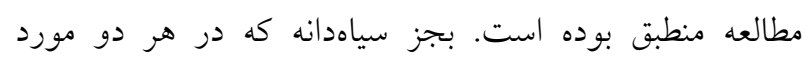

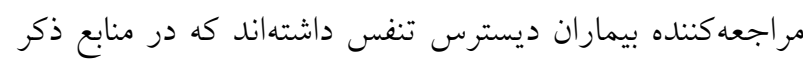

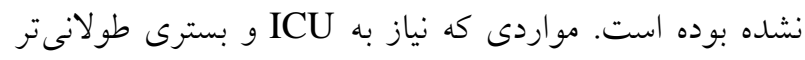

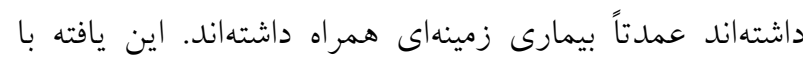

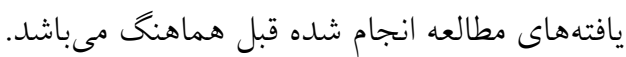

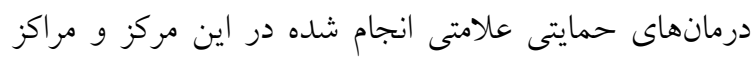

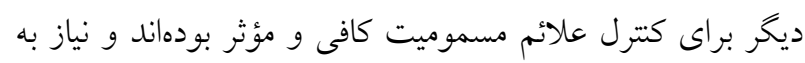

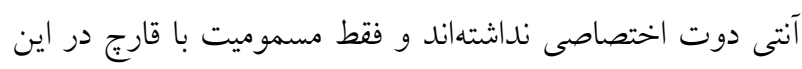

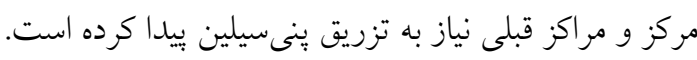

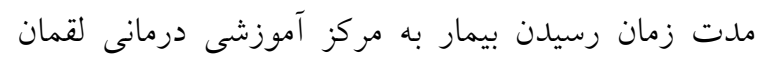

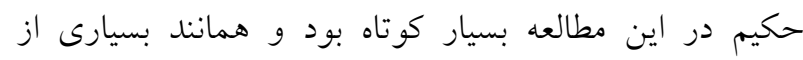

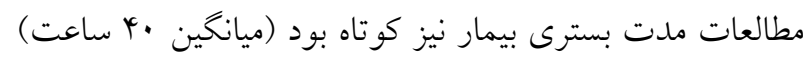

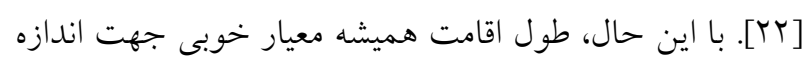

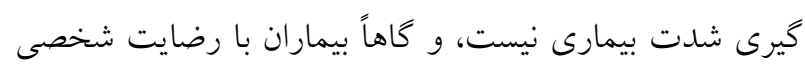

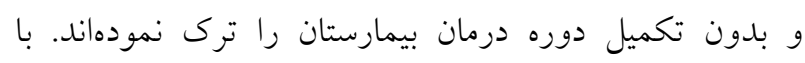
وجود عدم مورتاليتى و موربيديتى مهم، نبايد مسموميت كياهان

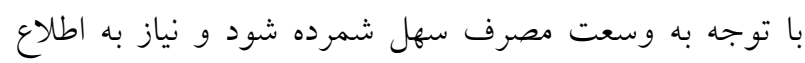
رسانى كامل در رسانههاى عمومى، فرهنخسازى، كنترل مر اكز

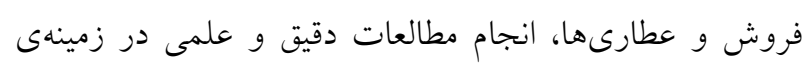

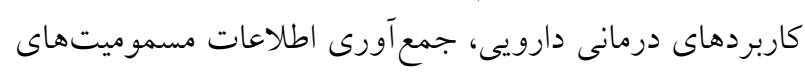

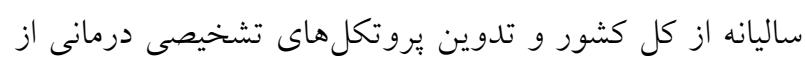
اقداماتى هستند كه نياز به بررسى و وييخيرى دارند.

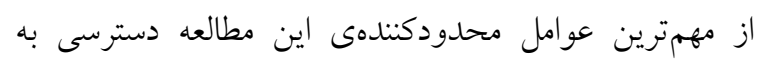

اطلاعات بايكانى شده بود. براى مسموميت با كياهان و قاريجها كدهاى مشخص و طبقهبندى موجود نمى باشد و اكثراً در كنار

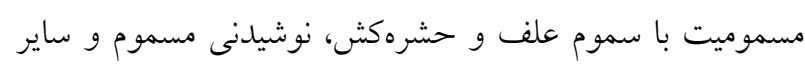

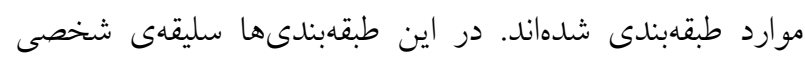

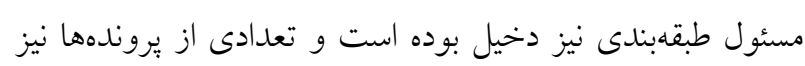

رنخ گياهان، عدم توانايى خواندن برجسب هاى هشداردهنده، سم

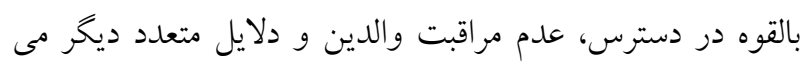

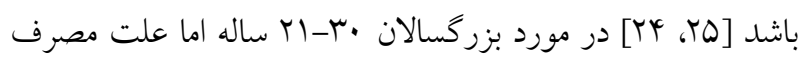

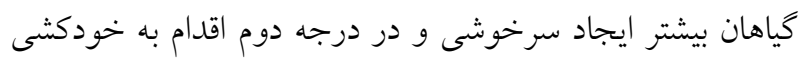

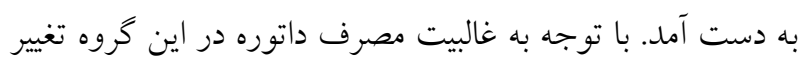

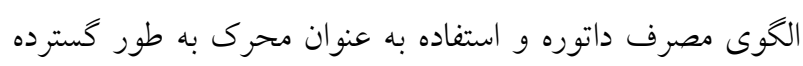
قابل توجه است. در اين مطالعه سوء استفاده از قطعات كياهى داتوره، در

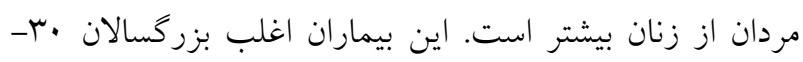

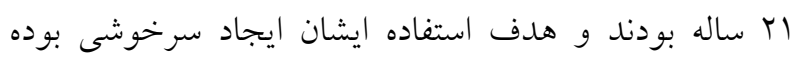

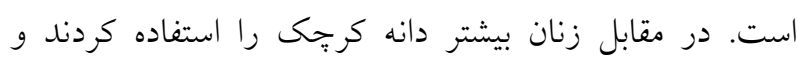
غالب مسموميتها در زنان اتفاقى و در درجه دوم استفاده

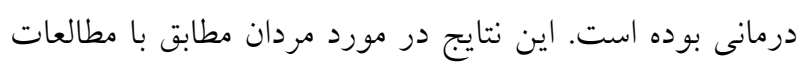

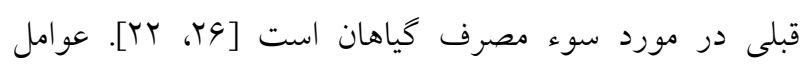

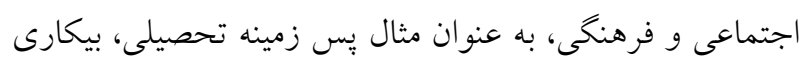

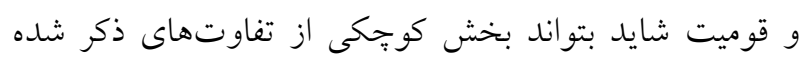

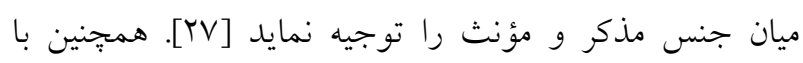

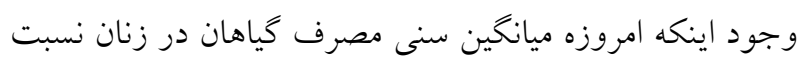

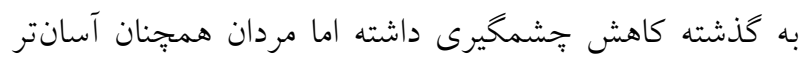

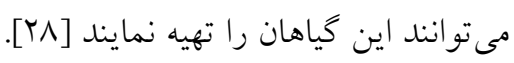

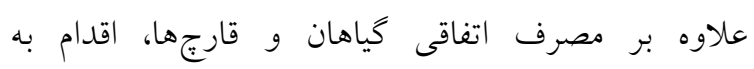

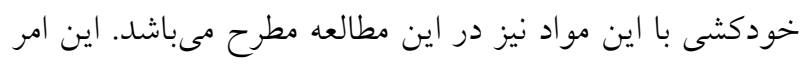

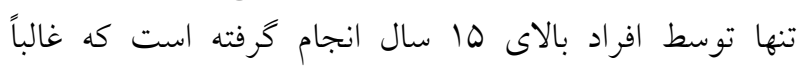

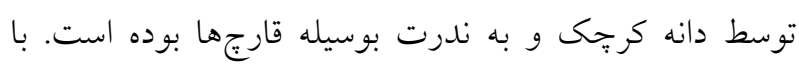

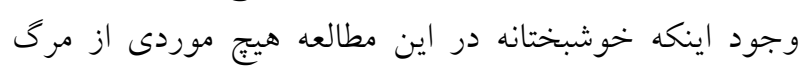

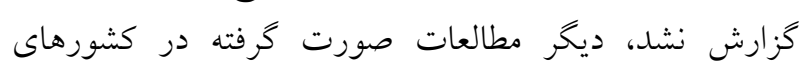

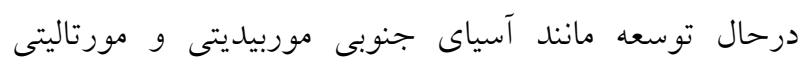
بالايى را يس از اقدام به خودكشى خصوصاً توسط كياهانى تونى

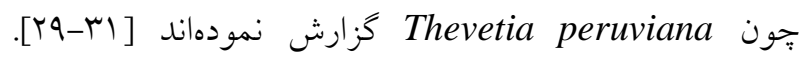

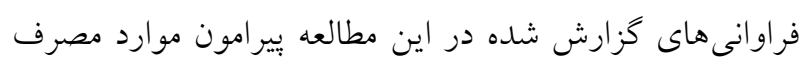
اتفاقى، درمانى و اقدام به خودكشى بسيار نزديك بـ به دئ ديخر

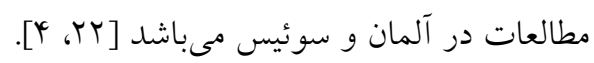
به طور كلى مسموميت با اكثر كياهان و قارجها علان علائم عمدتاً خفيف و غيراختصاصى دارند و در بسيارى از موارد به مانه 


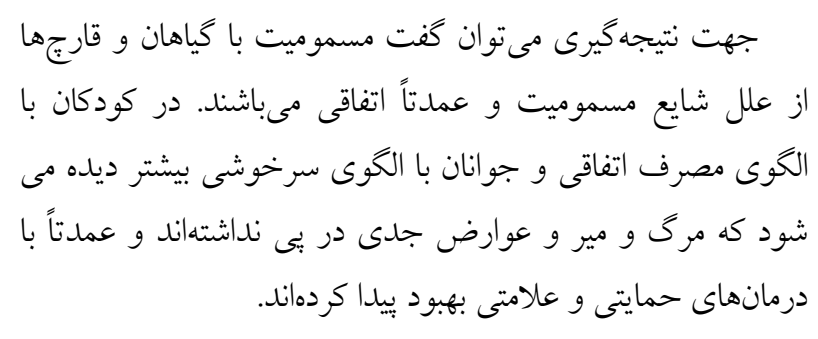

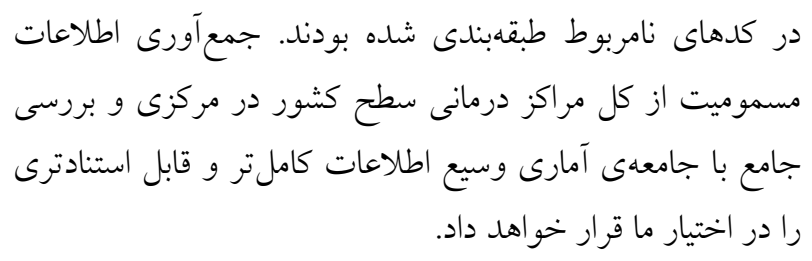

1. Bates BA and Burns MM. Potentially toxic plant ingestions in children: Clinical manifestations and evaluation. 2018 UpToDate.

2. Wiegand TJ, DABAM $F$ and Traub SJ. Clinical manifestations and evaluation of mushroom poisoning. UpToDate, July. 2013, 15.

3. Amini $\mathrm{M}$, Khosrojerdi $\mathrm{H}$ and Afshari R. Acute Datura Stramonium poisoning in East of Iran - a case series. Avicenna J. Phytomedicine 2012; 2 (2): 86 - 9.

4. Pietsch J, Koch I, Hermanns-Clausen M, Hüller G, Wagner R and Dressler J. Pediatric plant exposures in Germany, 1998-2004. Clin. Toxicol. 2008 Jan 20; 46 (7): 686 - 91.

5. Jaspersen-Schib R, Theus L, GuirguisOeschger M, Gossweiler B and Meier-Abt PJ. Serious plant poisonings in Switzerland 19661994. Case analysis from the Swiss Toxicology Information Center. Schweiz Med Wochenschr. 1996; 126 (25): 1085 - 98.

6. Krenzelok EP and Mrvos R. Friends and foes in the plant world: a profile of plant ingestions and fatalities. Clin. Toxicol. 2011; 49 (3): 142 - 9.

7. Chang S, Wu M, Deng J, toxicology CL-... and human, 1999 undefined. Poisoning by Datura leaves used as edible wild vegetables. researchgate.net. Chang SS, Wu ML, Deng JF, Lee CC, Chin TF, Liao SJ. Vet Hum Toxicol. Poisoning by Datura leaves used as edible wild vegetables.Vet. Hum. Toxicol. Aug 1999; 41 (4): 242-5.

8. Krenzelok EP and Mrvos R. Friends and foes in the plant world: A profile of plant ingestions and fatalities. Clin. Toxicol. 2011; 49 (3): 142 - 9.

9. French L, care RH-P emergency. undefined. Carpe Philon-An unhappy camper with vomiting and seizures. journals.lww.com. Osterhoudt, Kevin C. French, L. Keith Hendrickson, Robert G. Pediatric Emergency Care Carpe Philon-An unhappy camper with vomiting and seizures. 2010; 26 (12): 938-941.

10. America SD-E medicine clinics of $\mathrm{N}$, undefined. Plant exposures: wilderness medicine. Elsevier. America SD-E medicine clinics of N, Plant exposures: wilderness medicine. Elsevier. 2004.

11. Downs C, Phillips J, Ranger A, journal LF-E medicine, 2002 undefined. A hemlock water dropwort curry: a case of multiple poisoning. emj.bmj.com. Downs C, Phillips J, Ranger A. Emerg. Med. J. A hemlock water dropwort curry: a case of multiple poisoning. 2002; 19 (5): 472-473.

12. Lin TJ, Nelson LS, Tsai JL, Hung DZ, Hu SC, Chan HM, et al. Common toxidromes of plant poisonings in Taiwan. Clin. Toxicol. 2009 Feb; 47 (2): $161-8$.

13. Nelson L, Lewin N, Howland $M$ and Hoffman R. Goldfrank's toxicologic emergencies. Nelson L, Lewin N, Howland M, Hoffman R. Goldfrank'stoxicologic emergencies. 2011.

14. Froberg B, Ibrahim D and Furbee RB. Plant Poisoning. Vol. 25, Emergency Medicine Clinics of North America. 2007, pp: 375 - 433.

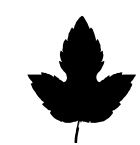


15. Strzelecki A, Pichon N, Gaulier JM, Amiel JB, Champy P and Clavel M. Acute Toxic Herbal Intake in a Suicide Attempt and Fatal Refractory Ventricular Arrhythmia. Basic Clin Pharmacol Toxicol. 2010 Mar 26; 107 (2): 698 - 9.

16. Suchard J, ... KW-A of emergency, 1998 undefined. Acute cyanide toxicity caused by apricot kernel ingestion. annemergmed.com. Suchard JR, Wallace KL, Gerkin RD. Acute cyanide toxicity caused by apricot kernel ingestion. Ann. Emerg. Med. 1998; 32 (6): 742-4.

17. Challoner K, Medicine MM-A of E. undefined. Castor bean intoxication. annemergmed.com. Challoner KR, Mc Carron MM. Castor bean intoxication. Ann. Emerg. Med. 1990; 19 (10): 1177-83.

18. Fleisher $G$ and Ludwig $S$. Textbook of pediatric emergency medicine. Fleisher G, Ludwig S. Textbook of pediatric emergency medicine.Sixth edition (May 20, 2010).

19. Disease-a-Month DB- 2009 undefined. Akee fruit and Jamaican vomiting sickness (Blighia sapida Köenig). diseaseamonth.com. Barceloux DG. Akee fruit and Jamaican vomiting sickness (Blighia sapida Köenig) Disease-a-Month J. 2009; 55 (6): 318-26.

20. Weigand TJ. Clinical manifestations and evaluation of mushroom poisoning [Internet]. UpToDate. 2016 [cited 2018 Feb 11]. p. 1-12. Available from: https://www.uptodate.com/contents/clinicalmanifestations-and-evaluation-of-mushroompoisoning

21. Plenert B, Prasa D, Hentschel $H$ and Deters M. Plant exposures reported to the Poisons Information Centre Erfurt from 2001-2010. Planta Med. 2012; 78 (5): 401 - 8.

22. Fuchs J, Rauber-Lüthy C, Kupferschmidt H, Kupper J, Kullak-Ublick G-A and Ceschi A. Acute plant poisoning: analysis of clinical features and circumstances of exposure. Clin. Toxicol. 2011; 49 (7): $671-80$.
23. Vichova $\mathrm{P}$ and Jahodar L. Plant poisonings in children in the Czech Republic, 1996-2001. Hum. Exp. Toxicol. 2003; 22 (9): 467 - 72.

24. Krenzelok EP. The use of poison prevention and education strategies to enhance the awareness of the poison information center and to prevent accidental pediatric poisonings. J. Toxicol. Clin. Toxicol. 1995; 33 (6): 663 - 7.

25. Tzimenatos L, Bond GR and Group PTES. Severe injury or death in young children from therapeutic errors: a summary of 238 cases from the American Association of Poison Control Centers. Clin. Toxicol. 2009; 47 (4): 348 - 54.

26. Carstairs SD and Cantrell FL. Peyote and mescaline exposures: a 12-year review of a statewide poison center database. Clin. Toxicol. 2010; 48 (4): 350 - 3.

27. Zilberman $\mathrm{M}$, Tavares $\mathrm{H}$ and El-Guebaly $\mathrm{N}$. Gender Similarities and Differences: The Prevalence and Course of Alcohol and Other Substance-Related Disorders. J. Addict. Dis. 2004; 22 (4): 61 - 74.

28. Tuchman E. Women and addiction: the importance of gender issues in substance abuse research. J. Addict. Dis. 2010; 29 (2): 127 - 38.

29. Eddleston M and Warrell DA. Management of acute yellow oleander poisoning. Oxford University Press; 1999.

30. Bandara V, Weinstein SA, White $\mathrm{J}$ and Eddleston M. A review of the natural history, toxinology, diagnosis and clinical management of Nerium oleander (common oleander) and Thevetia peruviana (yellow oleander) poisoning. Toxicon 2010; 56 (3): 273 - 81.

31. Eddleston M, Ariaratnam CA, Meyer WP, Perera G, Kularatne AM, Attapattu S and et al. Epidemic of self-poisoning with seeds of the yellow oleander tree (Thevetia peruviana) in northern Sri Lanka. Trop. Med. Int. Heal. 1999; 4 (4): $266-73$.

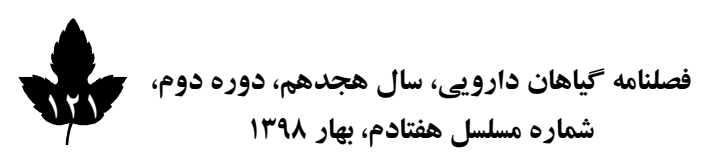




\title{
Epidemiological Survey of Poisoning by Plants and Mushrooms in Loghman-e- Hakim Hospital of Tehran, Iran, 2007 - 2013
}

\author{
Sattarzad Fathi S (M.D.) ${ }^{1}$, Hassanian-Moghaddam H (M.D.) ${ }^{2}$, Shadnia Sh (M.D.) ${ }^{2}$, Zamani N \\ (M.D.) $^{2}$, Rahimi M (M.D.) ${ }^{2 *}$ \\ 1- School of Medicine, Shahid Beheshti University of Medical Sciences, Tehran, Iran \\ 2- Department of Clinical Toxicology, Loghman Hakim Hospital, School of Medicine, \\ Shahid Beheshti University of Medical Sciences, Tehran, Iran \\ *Corresponding author: Loghman Hakim Hospital, Kamali Ave., South Karegar St., \\ Tehran, Iran \\ Tel \& Fax: +98-21-55424041, Cell phone: +98-912-135-1330 \\ E-mail: mrahimi744@gmail.com
}

\begin{abstract}
Background: Because in today's societies, not only the nutritional role of plants and fungi is very high, but also the main basis of many drugs are plants and plant products, therefore one of the problems of clinical toxicologists is the toxicity of these products.

Objective: This study aimed to define the prevalence, symptoms, complications, effective treatments, type of substance use, the cause of intake, location, gender distribution and age of poisoning with herbs and mushrooms in hospitalized patients of Loghman Hakim Hospital in Tehran.

Methods: This is a retrospective study with questionnaire formulation. Patients reviewed from the beginning of 2007 to the end of 2013.

Results: of 103 cases of poisoning with plants and mushrooms $64.1 \%$ were male, and $35.9 \%$ were female. The mean age of patients was $21.59 \pm 30.51$ years. The most commonly used substance is Datura (34\%). On the other hand, sole mushroom ingestion was found in $5.8 \%$ of cases. The most significant source of plants and mushrooms was reported from herbal-shops $(27.18 \%)$. The reason behind intake was either random or euphoria. Four patients were admitted to the intensive care unit, and three patients needed intubation. The mean hospital stay was $1.64 \pm 1.28$ days. Ninety percent of the treatments were supportive, and $75.7 \%$ of the patients recovered without any clinical complications.

Conclusion: Poisoning with toxic plants and mushrooms is one of the frequent causes of intoxication that is often accidental. In children poisoning is inadvertent, but youth are more likely wanted to have euphoria. Treatment strategies are supportive and symptomatic.
\end{abstract}

Keywords: Emergency Treatment, Mushroom Poisoning, Poisoning, Toxic plants 